\title{
Calendar of Events
}

\section{Toward the Painless Emergency Department: Better for the Patients; Better for Us}

\author{
October 20, 2004 \\ 8:00 am - 12:30 pm \\ Moscone Center \\ San Francisco, CA
}

The American Society of Law, Medicine \& Ethics (ASLME) will sponsor the upcoming conference: Toward the Painless Emergency Department: Better for the Patients; Better for Us

This half-day conference has been planned in conjunction with the American College of Emergency Physicians 2004 Scientific Assembly, which will take place October 16-20, 2004.

Treatment of pain in the emergency department raises issues of management of problem patients, impact on patient satisfaction and outcomes, disparity in treatment, and legal and regulatory risks. Through presentations and interactive discussions, this conference will:

- identify gaps in pain management practice, skills, and knowledge;

- describe current and forthcoming emergency medicine pain research;

- analyze the impact of the pharmaceutical industry on pain management; and

- identify strategies for improvement, including using management tools and operationalizing guidelines, protocols, and clinical pathways.

In addition, the conference will identify policy and research priorities to advance the quality of pain management practices in the US and Canada.

Knox Todd, M.D., M.P.H., Rollins School of Public Health and

Sandra Johnson, J.D., LL.M., Saint Louis University School of Law are serving as the conference co-chairs.

For more information on ASLME conferences and events, please visit our website at www.aslme.org. 